\title{
Objetos de Aprendizagem como elementos facilitadores na Educação a Distância
}

\section{Learning Objects as enablers in Distance Education}

\author{
Mára Lúcia Fernandes Carneiro ${ }^{1}$ \\ Milene Selbach Silveira ${ }^{2}$
}

\begin{abstract}
RESUMO
A expansão da educação a distância e o avanço dos recursos tecnológicos traz consigo o desafio da estruturação de materiais didáticos adequados para apoiar as ações pedagógicas nesses cursos. Neste contexto encontra-se a proposta de materiais didáticos estruturados como "Objetos de Aprendizagem" (OAs). Considera-se, aqui, que, para além de um material digital, um OA precisa funcionar como um elemento facilitador do processo de ensino e de aprendizado; para que isso ocorra, ele deve explicitar seus objetivos pedagógicos e ser estruturado de tal forma que seja autocontido (no que se refere ao conteúdo abordado), permitindo ser reusado em outras atividades ou cursos, para além daquela para o qual foi projetado. Com foco na explicitação de seus objetivos pedagógicos, este artigo apresenta a análise de um conjunto de 65 objetos de aprendizagem produzidos no Núcleo de Apoio à Educação a Distância (NAPEAD) da Universidade Federal do Rio Grande do Sul (UFRGS), discutindo os achados desta pesquisa e o ponto de vista de alguns dos diferentes atores envolvidos no processo de produção e uso desses OAs.
\end{abstract}

Palavras-chave: objetos de aprendizagem; objetivos pedagógicos; educação a distância.

DOI: $10.1590 / 0104-4060.38662$

1 Universidade Federal do Rio Grande do Sul, Instituto de Psicologia. Porto Alegre, Rio Grande do Sul, Brasil. Rua Ramiro Barcelos, 2600 - sala 201B. CEP: 90035-003.

2 Pontifícia Universidade Católica do Rio Grande do Sul (PUCRS), Programa de Pós-Graduação em Ciência da Computação da Faculdade de Informática. Porto Alegre, Rio Grande do Sul, Brasil. Av. Ipiranga, 6681 - Prédio 32 - Sala 636. CEP: 90619-900. 


\begin{abstract}
The evolution of distance education and the spread of technological resources bring about the challenge of structuring appropriate learning materials to support educational activities in these courses. In this context the proposal of instructional materials developed as "Learning Objects" (LOs) arises. In the research presented here a LO, in addition to its position of digital material, needs to work as an enhancer element of the teaching and learning process; for this to occur, it must explain its pedagogical objectives and be structured in such a self-contained way (with regard to the addressed content), allowing it to be reused in other activities or courses, beyond its original design. Focusing on explicit teaching objectives, this paper presents the analysis of a set of 65 learning objects produced in the Support Center for Distance Education (Núcleo de Apoio à Educação a Distância - NAPEAD) of the Federal University of Rio Grande do Sul (UFRGS). It discusses the research findings and the point of view of some of the different actors involved in the process of production and use of these LOs.

Keywords: learning objects; pedagogical objectives; distance education.
\end{abstract}

\title{
Introdução
}

O conceito de "objetos de aprendizagem" surgiu no final dos anos 1990, mas sua utilização continua significativa com a expansão da educação a distância e o avanço dos recursos tecnológicos. Essa expansão pode ser comprovada através do Censo do Ensino Superior, que registra um crescimento de mais de $2000 \%$ no número de matriculados em cursos superiores a distância nos últimos dez anos (INEP, 2014). No mesmo período, constata-se uma expansão das redes de comunicação, atingindo regiões afastadas dos grandes centros urbanos, permitindo acesso à internet com mais velocidade e qualidade nos mais diversos locais do país.

No Brasil, os cursos a distância utilizam cada vez mais o suporte da internet e os ambientes virtuais de aprendizagem, o que traz junto o desafio da estruturação de materiais didáticos adequados para apoiar as ações pedagógicas nesses cursos.

Enquanto na década de 1990 o uso dos materiais impressos era o foco, com o desenvolvimento tecnológico e o maior acesso às redes, foram sendo desenvolvidos outros formatos e possibilidades para desenvolvimento de materiais didáticos. Esses materiais atualmente envolvem recursos tecnológicos e midiáticos, com o intuito de ampliar a interação dos estudantes com o material 
didático e apoiar o desenvolvimento das atividades pedagógicas de forma mais atrativa e, por que não, lúdica.

Dentre esses recursos, encontra-se a proposta de materiais didáticos estruturados como "Objetos de Aprendizagem" (OAs). Esses materiais têm os mais diversos formatos e propostas de uso, pois ainda não há consenso sobre as características que devem possuir para serem considerados como recursos pedagógicos que apoiem a aprendizagem. Algumas dessas características apontam a demanda por interfaces e recursos que estimulem os alunos a buscar novos conhecimentos e propiciar a aprendizagem de um determinado conteúdo. Diversos autores destacam as questões de reusabilidade (baseadas nos conceitos da programação orientada a objetos da área da Ciência da Computação, do início dos anos 1990) e de padronização, apontando a necessidade de definição de metadados para facilitar o armazenamento e localização dos objetos de aprendizagem (METROS; BENNET, 2002, p. 3; POLSANI, 2003, p. 2; METROS, 2005, p. 12; KOOHANG; HARMAN, 2007). Outra característica essencial dos OAs seria a necessidade de explicitação de seus objetivos pedagógicos. E é neste ponto que a pesquisa aqui apresentada se concentra.

Considera-se, aqui, que, para além de um material digital (como uma apresentação de slides ou um vídeo), um OA precisa funcionar como um elemento facilitador do processo de ensino e de aprendizado; para que isso ocorra, ele deve explicitar seus objetivos pedagógicos e ser estruturado de tal forma que seja autocontido (no que se refere ao conteúdo abordado), permitindo ser reusado em outras atividades ou cursos, para além daquela para o qual foi projetado.

Esse artigo está estruturado da seguinte forma: inicialmente apresenta-se uma breve revisão teórica sobre definições e conceitos de objetos de aprendizagem, com o objetivo de estabelecer um conjunto de características (ou condições) que permitam identificar um material didático digital como tal. A terceira seção descreve a metodologia e o objetivo da pesquisa, contextualizando seu foco na produção e análise de OAs desenvolvidos no Núcleo de Apoio à Educação a Distância (NAPEAD) da Universidade Federal do Rio Grande do Sul (UFRGS). A quarta seção apresenta um aprofundamento desta discussão, com o ponto de vista de alunos e professores sobre os OAs construídos. Por fim, a quinta seção apresenta as considerações finais deste trabalho.

\section{Objetos de aprendizagem}

Desde o início dos anos 2000, o termo Objetos de Aprendizagem (OA) é utilizado para descrever materiais didáticos desenvolvidos para apoio aos 
processos de ensino e aprendizagem. Inúmeras são as definições propostas para esse termo, cuja origem é atribuída a Hodgins $(2000,2002)$. Esse autor trouxe a ideia dos blocos de LEGO $^{\mathrm{TM}}$ para associar às possibilidades de reuso de um objeto de aprendizagem, de acordo com as necessidades e características do aprendiz (HODGINS, 2002, p. 76).

Wiley (1999) questiona a metáfora dos blocos de LEGO ${ }^{\mathrm{TM}}$ proposta por Hodgins. Wiley considera esta metáfora como simplificadora, já que omitiria o desafio de criar experiências educacionais efetivas, associadas a avaliações que permitissem verificar se os objetivos pedagógicos foram atingidos. No entanto, ele propõe uma definição muito simples, afirmando que um OA é "qualquer recurso digital que pode ser reusado para apoiar a aprendizagem" (WILEY, 2000 , p. 7). Wiley $(2002$, p. 17) propõe também a metáfora do "átomo" em contraponto à metáfora de Hodgins. Na metáfora do átomo, Wiley parte da ideia de que um átomo é um pequeno componente, que pode ser combinado e recombinado com outros átomos para formar uma molécula, ou seja, um todo maior. Esse autor explicita que os átomos são diferentes dos blocos de LEGO ${ }^{\mathrm{TM}}$ porque: (1) nem todo átomo pode ser combinado com qualquer átomo; (2) os átomos só podem ser combinados em certas estruturas prescritas, dependentes de sua estrutura interna; e, (3) é necessário algum conhecimento específico para conseguir combiná-los e compor uma estrutura maior. Essas três condições apontam algumas das características esperadas de um objeto de aprendizagem.

O grupo de trabalho Learning Object Metadata (LOM) do Institute of Electrical and Electronics Engineers (IEEE) propôs uma definição ampla e não específica para um objeto de aprendizagem, estabelecendo que um OA é "qualquer entidade, digital ou não digital, que pode ser usada, reutilizada ou referenciada durante a aprendizagem apoiada por tecnologia" (IEEE, 2002, p. 6). Essa definição permitiria considerar tanto um computador como uma imagem digital como OAs da mesma categoria. O mérito do LOM recai na busca por metadados que pudessem descrever e detalhar um objeto de aprendizagem, propiciando sua reusabilidade.

Diversos autores (POLSANI, 2003; JOHNSON, 2003; TAROUCO et al., 2003; JOHNSON; HALL, 2007; KAY; KNAACK, 2008; BEHAR, 2009) associam o conceito de $\mathrm{OA}$ ao uso de materiais digitais e destacam características como a interatividade e reusabilidade.

Nikolopoulos et al. (2012), por um lado, analisam as características de OAs necessárias para que sejam utilizados em cursos a distância, destacando a acessibilidade (especificação de metadados que permitam ser armazenados e referenciados em um banco de dados), reusabilidade (de forma a poderem ser usados em diferentes contextos) e interoperabilidade (independência do tipo de mídia em que foi produzido e dos diversos tipos de sistemas e gerenciamentos 
de conteúdo). A partir dessas condições, os autores propõem uma definição para OA como "unidade de conteúdo digital, autocontida e independente, a qual está associada com um ou mais objetivos de aprendizagem e tem como objetivo primário a habilidade de reuso em diferentes contextos educacionais" (NIKOLOPOULOS et al., 2012, p. 113).

Já Metros e Bennet (2002) discutem as diferenças entre "objetos de informação" e "objetos de aprendizagem". Segundo as autoras, um objeto de informação é "um recurso digital que não inclui qualquer estrutura instrucional" e não apresenta qualquer informação sobre quem é o desenvolvedor, como usá-lo e assim por diante. Um exemplo desse tipo de objeto seria uma animação descrevendo a erupção de um vulcão e poderia ser disponibilizado em uma biblioteca digital (METROS, BENNET, 2002, p. 3). Por outro lado, os objetos de aprendizagem seriam uma extensão dos objetos de informação, incluindo objetivos de aprendizagem, avaliações e outros componentes instrucionais. As autoras também destacam que, caso esses componentes não estejam incluídos no objeto de aprendizagem, poderiam ser associados a eles, através de links. Como exemplo, poderíamos citar um hipertexto, onde seriam descritos os objetivos de aprendizagem para o estudo da erupção de um vulcão e um instrumento de avaliação, que permitisse que o aluno avaliasse sua aprendizagem sobre o tema. Nesse hipertexto poderia estar contida a animação citada anteriormente, constituindo então um objeto de aprendizagem. Assim, o objeto de informação estaria contido em um objeto de aprendizagem, que poderia ser disponibilizado em um repositório. É interessante essa análise, que traz em si um questionamento importante sobre as características e demandas de um objeto de aprendizagem: a importância da descrição dos seus objetivos pedagógicos.

Neste artigo adota-se o conceito de OA como quaisquer materiais eletrônicos (como imagens, vídeos, páginas web, animações ou simulações), desde que tragam informações destinadas à construção do conhecimento (conteúdo autocontido), explicitem seus objetivos pedagógicos e estejam estruturados de tal forma que possam ser reutilizados e recombinados com outros objetos de aprendizagem (padronização).

Além disto, no Quadro 1 destacamos sete condições para que um determinado recurso educacional seja considerado um objeto de aprendizagem (SILVEIRA; CARNEIRO, 2012).

Duas das condições para um recurso educacional ser um OA, apresentadas no Quadro 1, são "Explicitar claramente um objetivo pedagógico" e "Ser autocontido". Acreditamos que ambas - além de definitivas para caracterização de um OA - devem ser vistas como uma unidade: para que um objeto seja realmente autocontido, além de ser suficiente em relação a um determinado assunto (sem que seu usuário precise de outros materiais para entendê-lo), é necessário 
QUADRO 1 - CONDIÇÕES PARA UM RECURSO EDUCACIONAL SER CONSIDERADO UM OA

\begin{tabular}{|l|l|}
\hline \multicolumn{1}{|c|}{ Condição } & \multicolumn{1}{c|}{ Detalhamento } \\
\hline $\begin{array}{l}\text { Explicitar } \\
\text { claramente um } \\
\text { objetivo pedagógico }\end{array}$ & $\begin{array}{l}\text { Propiciar orientações claras para que o aluno saiba o que se } \\
\text { espera que ele aprenda ao usar o objeto de aprendizagem e } \\
\text { o professor (distinto de quem produziu o objeto) saiba como } \\
\text { poderia usar o mesmo. }\end{array}$ \\
\hline Priorizar o digital & $\begin{array}{l}\text { Priorizar o desenvolvimento de objetos de aprendizagem que } \\
\text { não necessitem, para sua utilização, de aplicativo ou programa } \\
\text { que não esteja disponível gratuitamente na web. }\end{array}$ \\
\hline $\begin{array}{l}\text { Prover auxílio aos } \\
\text { usuários }\end{array}$ & $\begin{array}{l}\text { Oferecer auxílio ao usuário via interface e via instruções } \\
\text { facilmente acessíveis. }\end{array}$ \\
\hline $\begin{array}{l}\text { Proporcionar } \\
\text { interatividade }\end{array}$ & $\begin{array}{l}\text { Proporcionar que o usuário possa interagir, executando ações } \\
\text { com o objeto. }\end{array}$ \\
\hline $\begin{array}{l}\text { Proporcionar } \\
\text { interação }\end{array}$ & $\begin{array}{l}\text { Permitir ações entre os usuários (alunos, professores, tutores, } \\
\text { etc.) a partir do e/ou no objeto. }\end{array}$ \\
\hline $\begin{array}{l}\text { Fornecer feedback } \\
\text { constante }\end{array}$ & $\begin{array}{l}\text { Manter o usuário sempre informado do estado atual de sua } \\
\text { interação com o OA. }\end{array}$ \\
\hline Ser autocontido & $\begin{array}{l}\text { Ter foco em um determinado assunto e o explicar sem } \\
\text { necessariamente depender de outros objetos e/ou materiais. }\end{array}$ \\
\hline
\end{tabular}

FONTE: Silveira e Carneiro (2012).

que ele contenha claramente especificados quais objetivos pedagógicos que pretende que se alcance com seu uso.

Neste âmbito se delineou o objetivo desta pesquisa: verificar como objetos de aprendizagem apresentam os objetivos pedagógicos a eles relacionados, de forma a permitir que sejam elementos facilitadores do processo de ensino e de aprendizado.

A fim de buscar dados neste sentido, uma análise de um conjunto de 65 OAs foi realizada, conforme detalhado na próxima seção.

\section{Análise de objetos de aprendizagem com foco em seus objetivos pedagógicos}

As seções a seguir apresentam a metodologia utilizada neste estudo, o contexto de aplicação do mesmo, a análise em si e uma discussão dos achados de pesquisa. 


\section{Metodologia}

A pesquisa, de cunho exploratório, envolveu a análise de um conjunto de objetos de aprendizagem produzidos pelo Núcleo de Apoio Pedagógico à Educação a Distância (NAPEAD) da Universidade Federal do Rio Grande do Sul (UFRGS), objetos estes elaborados em conjunto com os professores da UFRGS. Como esses objetos foram desenvolvidos com o apoio da Coordenação de Aperfeiçoamento de Pessoal de Nível Superior (CAPES), através do programa Universidade Aberta do Brasil (UAB) e recursos da UFRGS, seu acesso é livre a partir do portal da Universidade (www.ufrgs.br/napead/repositório).

Assim, a escolha deste conjunto específico deu-se, principalmente, por seu livre acesso pela comunidade (o que permite que outros pesquisadores possam reproduzir a pesquisa, caso desejado) e pelas diferentes áreas do conhecimento aos quais se destinam.

Dentre as características analisadas, priorizou-se a busca por informações de cunho pedagógico, que permitissem avaliar se os objetivos estavam claramente explicitados no próprio objeto de aprendizagem, atendendo ao objetivo da pesquisa.

Para esta análise, todos os 65 objetos disponibilizados no referido portal foram inspecionados, em busca de informações que apoiassem a discussão aqui realizada. Para cada um dos objetos disponibilizados, foram catalogados:

- Título do objeto;

- Área do conhecimento;

- Tecnologia utilizada para sua construção;

- Identificação de:

- Objetivo Geral;

- Objetivo (Proposta) Pedagógico;

- Instruções de Uso;

- Instruções (de cunho pedagógico) para os Alunos;

- Instruções (de cunho pedagógico) para os Professores.

- Excertos de texto, refletindo tratamento de questões pedagógicas.

Após esta catalogação, foi realizada a análise e discussão dos dados obtidos.

\section{Contexto de Aplicação}

O NAPEAD foi criado em 2009 pela Secretaria de Educação a Distância (SEAD) da UFRGS, com o apoio da UAB/CAPES, como um espaço para apoio à produção de objetos de aprendizagem digitais para todas as iniciativas em EAD da Universidade. 
O núcleo é coordenado por professores com experiência em EAD e Informática na Educação e reúne uma equipe de profissionais e bolsistas que têm por objetivo apoiar essa produção de forma colaborativa, tornando o professor proponente um parceiro ativo no processo de implementação, teste e avaliação dos seus objetos de aprendizagem (NITZKE; CARNEIRO; PASSOS, 2011). Atualmente a equipe conta, além de sua coordenação (professor da área de Design), com uma pedagoga, um programador visual e oito bolsistas, estes últimos com experiência na produção de vídeos, animações e hipertextos.

As metodologias utilizadas para produção de objetos são descritas na próxima seção, seguidas pelas características principais dos objetos atualmente disponíveis para a comunidade.

Metodologias de Produção

Quando o NAPEAD iniciou suas atividades, não havia uma metodologia prévia para orientar e apoiar o processo de produção dos objetos de aprendizagem. Assim, após a apresentação de uma proposta de conteúdo a ser transformado em objeto de aprendizagem à coordenação do núcleo, a equipe iniciava a implementação a partir da interação direta entre o bolsista designado para o projeto e o professor responsável. Nem o bolsista nem o professor tinham a compreensão completa do conceito de objeto de aprendizagem e, muitas vezes, limitavam-se a organizar um hipertexto ou produzir uma animação, a partir de esquemas já utilizados pelo professor em sala de aula.

A partir das dificuldades daí decorrentes, a coordenação do núcleo passou a esboçar uma proposta de metodologia, envolvendo as seguintes etapas (NITZKE; CARNEIRO; PASSOS, 2011):

1. Sensibilização dos professores da Universidade e potenciais produtores de objetos de aprendizagem, através da realização de seminários e reuniões;

2. Capacitação dos professores proponentes, para conhecerem as potencialidades das tecnologias disponíveis e definir quais as mais adequadas para seus objetivos pedagógicos;

3. Elaboração do projeto e submissão à coordenação do núcleo para análise;

4. Implementação pela equipe de bolsistas;

5. Testagem e finalização, envolvendo a avaliação do objeto produzido pelo professor proponente. 
A partir de 2011, foi adotada a metodologia INTERAD - Interfaces Interativas Digitais aplicadas à Educação (Figura 1), com a intenção de qualificar o trabalho e aprimorar o processo de produção de objetos de aprendizagem pelo NAPEAD.

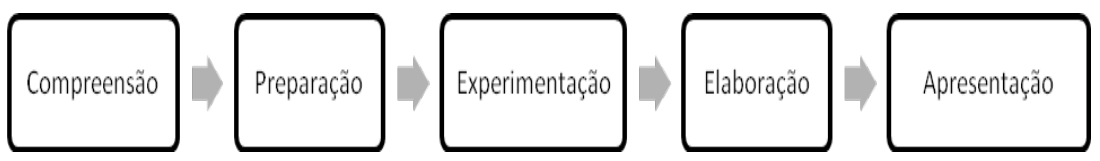

FIGURA 1 - METODOLOGIA INTERAD

FONTE: Schwanck, Carneiro e Silveira (2014).

Essa metodologia orienta o desenvolvimento de interfaces para materiais educacionais digitais, e está dividida em cinco etapas (PASSOS, 2011):

- Compreensão: busca de subsídios para o projeto, levantamento de informações relativas ao tema, objetivos pedagógicos, necessidades do usuário, público-alvo, filosofia da instituição, conceito visual do material e contexto de aplicação;

- Preparação: descrição de elementos e funcionalidades necessárias para atingir os objetivos pedagógicos propostos; definição de equipe; seleção de recursos interativos e de mídia apropriada; levantamento de conteúdo;

- Experimentação: organização do conteúdo conforme a proposta interativa; design de interação; desenho dos fluxos de tarefa;

- Elaboração: projeto gráfico; definição da hierarquia da informação; composição dos elementos gráficos através de modularização; agrupamento do conteúdo;

- Apresentação: design visual; definição dos atributos gráficos e apresentação de textos e imagens.

Conforme descrito por Nitzke, Carneiro e Passos (2011), durante o planejamento para a aplicação dessa metodologia, percebeu-se a necessidade da sua adaptação às tecnologias e ao modelo de processo já estabelecido no núcleo. Além disso, a metodologia INTERAD propunha um processo linear e sequencial, não levando em conta a ideia de "ciclo de vida", adotada na Engenharia de Software, e não propiciando etapas de avaliação e correção de eventuais desvios da proposta inicial.

Ao longo de 2012 e 2013, foi realizado um levantamento das atividades realizadas durante a produção de objetos de aprendizagem (produção esta ocorrida entre dezembro de 2010 a janeiro de 2013). Este acompanhamento foi realizado por meio da análise dos registros feitos no software Redmine (http:// 
www.redmine.org/), um gerenciador de projetos em software livre, adotado pelo Núcleo. Além disso, foram realizadas entrevistas com 24 dos 58 professores proponentes de projetos implementados pelo NAPEAD e que geraram os 65 objetos aqui em análise.

Essas observações permitiram identificar que as etapas, inicialmente propostas, foram sendo adaptadas e detalhadas ao longo da implementação e adoção da metodologia INTERAD, gerando um ciclo como o mostrado na Figura 2.

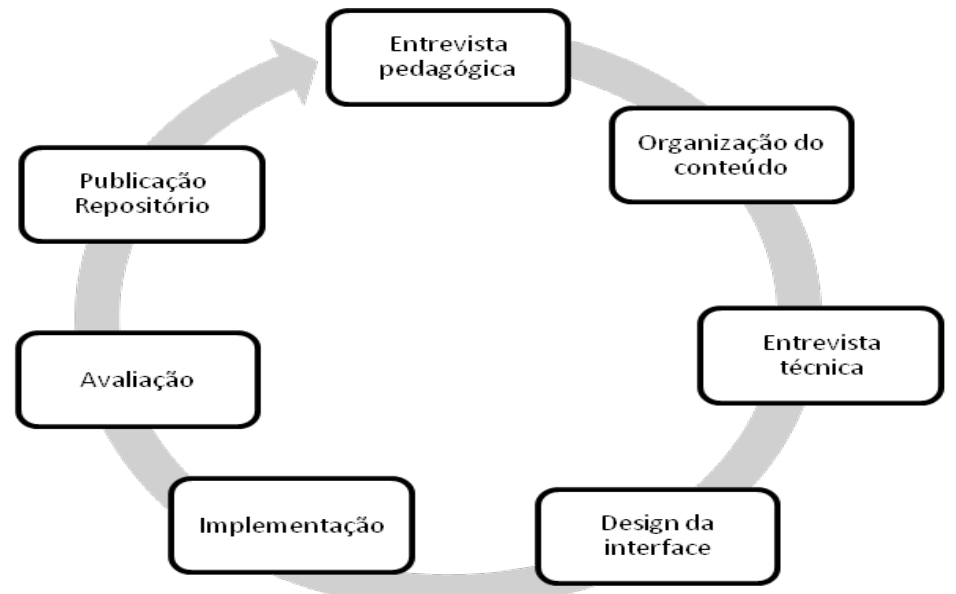

FIGURA 2 - METODOLOGIA REFORMULADA

Fonte: Elaborada pelas autoras (2014).

As etapas foram renomeadas e detalhadas, envolvendo:

- Entrevista pedagógica: reunião da assessoria pedagógica com o professor para explicitação do projeto e suas características. Oportunidade de a equipe explicar as características esperadas de um OA e auxiliar na reformulação/detalhamento do storyboard (ou roteiro ou mapa de navegação) e definição da interface;

- Organização do conteúdo: análise do conteúdo, encaminhado pelo professor, pela equipe técnica, avaliando a complexidade e sua vinculação com o storyboard. Elaboração de proposta de implementação;

- Entrevista técnica: reunião entre a equipe responsável pelo projeto e o professor proponente, para apresentação da proposta de implementação e refinamento;

- Design da interface: elaboração de wireframe e da proposta de interface, analisada e aprovada pelo professor proponente; 
- Implementação: etapa de programação, acompanhada pelo coordenador de equipe. O professor é consultado quando há dúvida quanto a detalhes de conteúdo e estruturação;

- Avaliação: apresentação da versão final ao professor proponente, para testes e avaliação. Após sua aprovação, a coordenação do projeto também realiza avaliação exploratória. Caso identifique alguma correção, retorna para a fase de Implementação;

- Publicação no repositório: disponibilização do OA para a comunidade, no formato de acesso livre.

Essa metodologia continua em análise e constante aprimoramento, a partir das experiências de sua aplicação na produção de novos objetos de aprendizagem. A próxima seção apresenta as características gerais dos OAs analisados.

Características dos Objetos de Aprendizagem analisados

Em termos de abrangência, um dos motivos da escolha deste repositório, os objetos disponibilizados à comunidade pelo NAPEAD compreendem todas as áreas do conhecimento, como mostrado na Figura 3.

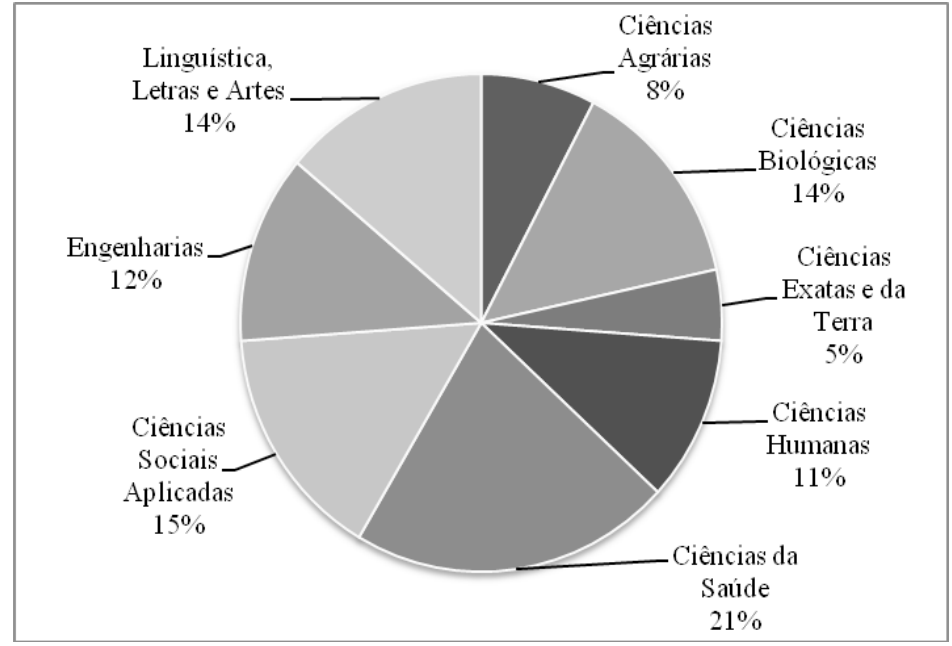

FIGURA 3 - DISTRIBUIÇÃO DOS OAs DESENVOLVIDOS NO NAPEAD POR ÁREA DE CONHECIMENTO

FONTE: Elaborada pelas autoras (2014). 
Além disto, estes objetos foram construídos utilizando-se diferentes tecnologias, conforme apresentado na Figura 4.

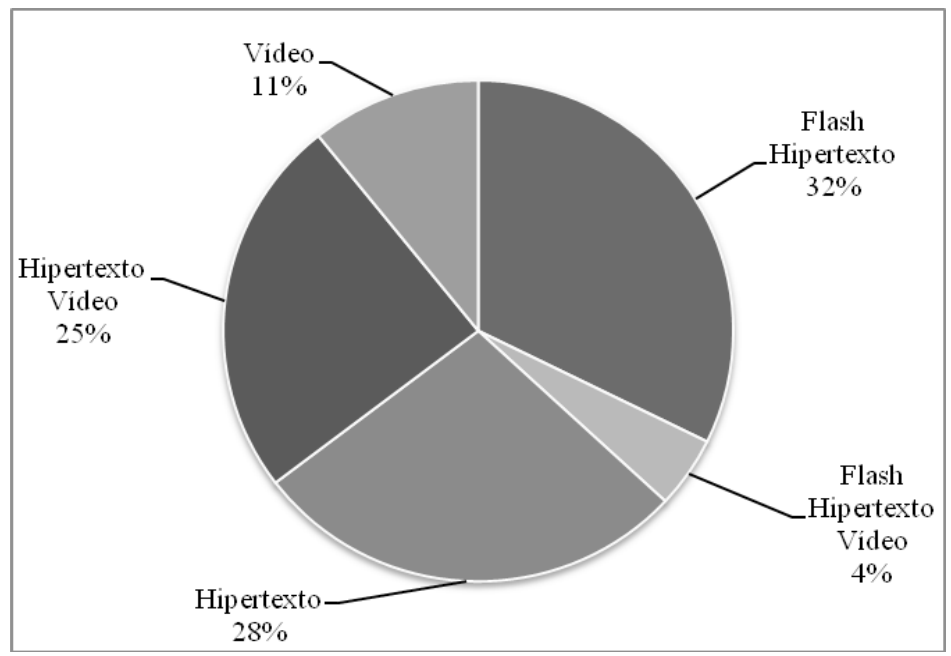

FIGURA 4 - TECNOLOGIAS UTILIZADAS NA CONSTRUÇÃO DOS OAs FONTE: Elaborada pelas autoras (2014).

A diversificação de tecnologias permite que os conteúdos por eles trabalhados possam ser veiculados de diferentes formas, propiciando, por exemplo, desde leituras não lineares, como no uso de hipertexto (Figura 5), até demonstrações, com o uso de vídeos (Figura 6), e simulações, com o uso de animações (Figura 7). O gráfico da Figura 4 permite verificar que $61 \%$ dos objetos desenvolvidos envolvem mais de uma tecnologia, possibilitando, também, diferentes olhares ao conteúdo em foco.

Dados relativos à área de conhecimento associada ou tecnologia utilizada para seu desenvolvimento são facilmente coletáveis pelo repositório. Para captura dos demais dados, foi necessária a exploração de cada objeto individualmente.

Em relação à apresentação do objetivo geral de cada objeto, mais da metade deles o apresenta, mas nem sempre em destaque. Dos 65 objetos analisados, $43(66 \%)$ apresentam seu objetivo, sendo que em 31, o objetivo está destacado dentro do Objeto e nos outros 12, há apenas sua descrição na janela de acesso do Repositório (item destacado como Descrição do Objeto na Figura 8), o que pode passar despercebido para alguns usuários. 


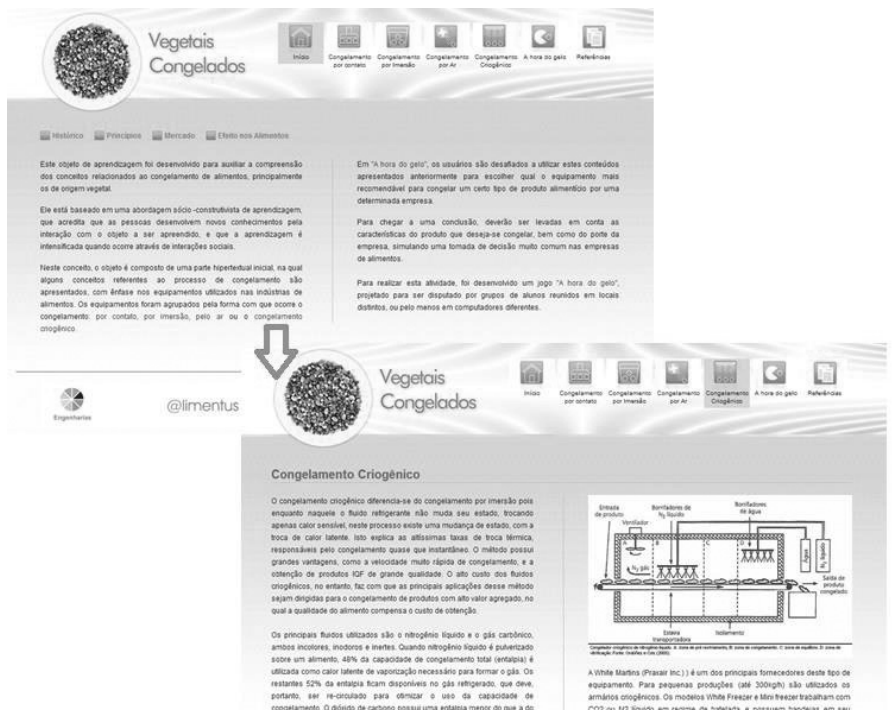

FIGURA 5 - EXEMPLO DE OA UTILIZANDO HIPERTEXTO: VEGETAIS CONGELADOS

FONTE: Nitzke (2012).

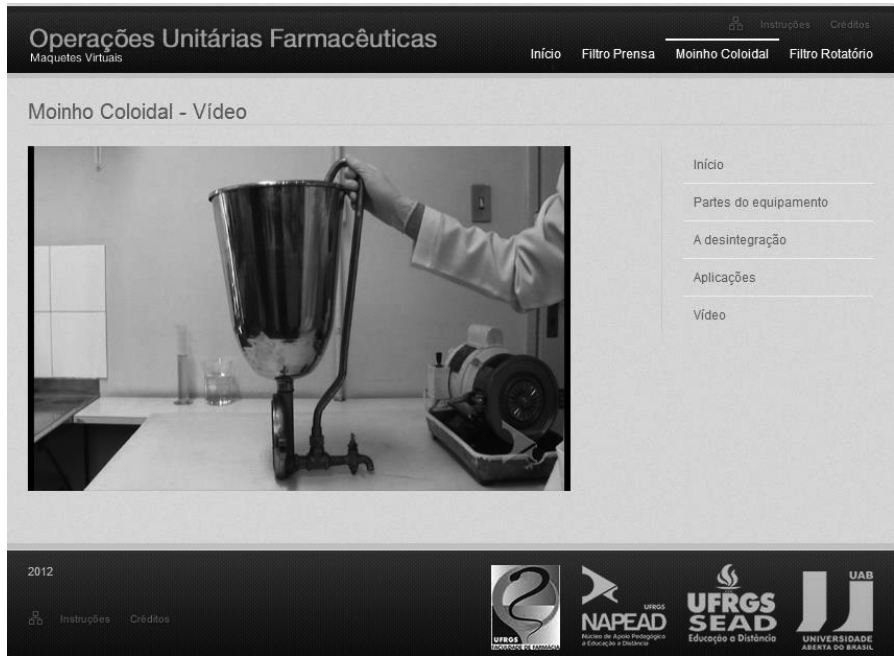

FIGURA 6 - EXEMPLO DE OA UTILIZANDO VÍDEO: OPERAÇÕES UNITÁRIAS FARMACÊUTICAS - MOINHO COLOIDAL

FONTE: Apel (2011). 


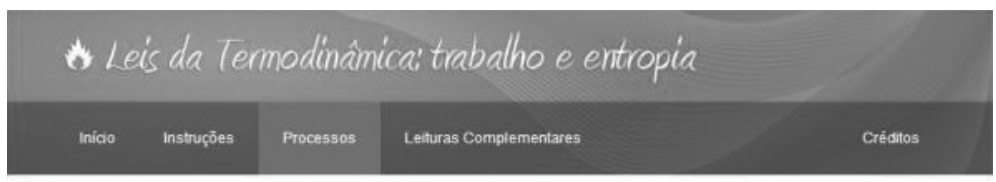

\section{Processo Reversivel}

Processo Reversivel

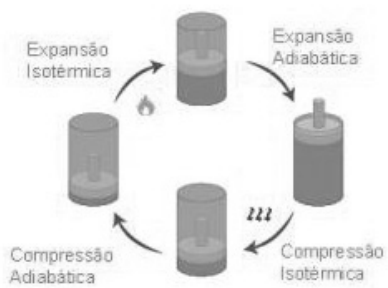

Processo Ireversivel

O ciclo de Camot is caracterizado como um processo cidico reversivel envolvendo đuas transtormaç̧̃es isotérmicas e duas adiabáticas.

A animação representa um ciclo onde o estado inicial está inicialmente assinalado. Ao lado vocế poderă observar a expansão ou compreensăo que está sendo representada no gráfico e, simultaneamente, analisar como se comporta a relaçăo entre Temperatura e Entropia
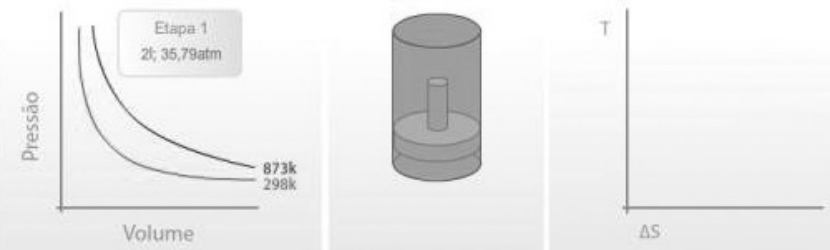

$\Delta S$

FIGURA 7 - EXEMPLO DE OA UTILIZANDO ANIMAÇÕES EM FLASH: $1^{\mathrm{a}}$ e $2^{\mathrm{a}}$ LEIS DA TERMODINÂMICA

FONTE: Weibel (2012).

A descrição destes objetivos geralmente é restrita à apresentação da finalidade do objeto em questão, em termos como: "proporcionar o entendimento", "avaliar seus conhecimentos [do aluno]", "disponibilizar um referencial", "familiarizar o aluno", "refletir sobre", "apresentar" ou "auxiliar a compreensão", por exemplo. Cabe destacar que essa janela foi construída pela equipe responsável pelo Repositório, a partir dos dados fornecidos no projeto original (após consulta e autorização do professor projetista).

A análise e a discussão sobre a explicitação dos objetivos pedagógicos associados ao uso de cada um destes OAs, sendo o foco principal desta pesquisa, serão discutidas em detalhe na próxima seção. 


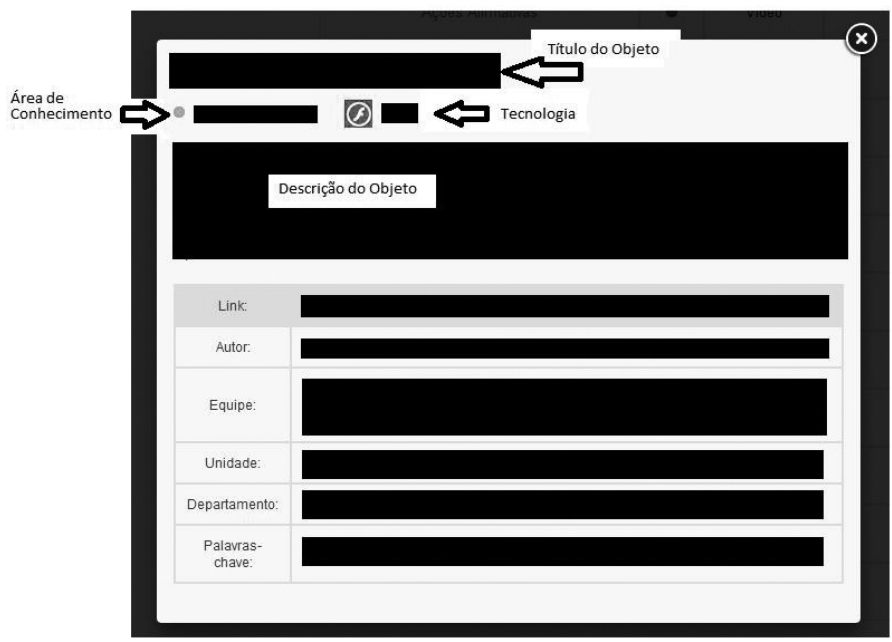

FIGURA 8 - EXEMPLO DE JANELA DE ACESSO A CADA OA NO REPOSITÓRIO DO NAPEAD

FONTE: Adaptado a partir de <http://www.ufrgs.br/napead/repositorio/>.

\section{Análise dos OAs}

Os objetos foram analisados a fim de se verificar como (e se) cada um deles apresenta seu objetivo pedagógico. Conforme citado anteriormente, isto significa o quanto eles propiciam "orientações claras para que o aluno saiba o que se espera que ele aprenda ao usar o objeto de aprendizagem e o professor (distinto de quem produziu o objeto) saiba como poderia usar o mesmo." (SILVEIRA; CARNEIRO, 2012).

Da análise realizada, diagnosticou-se que, dos 65 objetos analisados, apenas $5(7,7 \%)$ apresentavam clara e destacadamente o objetivo (proposta) pedagógica do OA, e de outros $12(18,5 \%)$, esta proposta podia ser inferida a partir de uma leitura mais aprofundada de todos os seus itens (introdução, apresentação, etc.).

Muitas destas informações dizem respeito a conteúdos e/ou habilidades que podem ser apreendidos e/ou desenvolvidos ${ }^{3}$ :

3 Material produzido pelos professores projetistas dos objetos de aprendizagem analisados e disponíveis nos próprios objetos, publicados no repositório do NAPEAD (http://www.ufrgs.br/ napead/repositorio/). 
Além de referencial histórico, o conteúdo, pelo [...], permitirá apreender a relação dessa prática profissional articulada e contextualizada em diferentes âmbitos como os econômicos, sociais, politicos e culturais.

Material de referência da disciplina [...], que substitui a utilização de livro texto, com a vantagem de permitir a disponibilização de links para outros recursos de texto ou audiovisuais correlatos aos assuntos abordados. As habilidades a serem desenvolvidas compreendem a seleção e uso adequado de [...].

[...] facilitará ao estudante situar-se temporal e geograficamente e permitirá cruzamentos de informações em âmbito global e local.

Outras destacam pontos de maior protagonismo do aluno neste contexto, como em:

Através de seu uso pretende-se disponibilizar um método mais interativo de aprendizagem que permita integração entre conteúdos teóricos e a sua aplicação na [...], possibilitando ao usuário estabelecer [...] consolidando as informações disponibilizadas.

Histórias de situações [...] que permitem diferentes possibilidades e níveis de complexidade de estabelecimento de [...]. As histórias se desenvolvem de maneira a permitir que os alunos exercitem o enfrentamento de situações de [...] compreendendo a interação entre questões [...]. Também se pretende exercitar a compreensão do conceito de [...].

São também destacados momentos de ensino em que os objetos podem ser utilizados:

Vão servir como objetos de aprendizagem adicionais às aulas presenciais, estimulando os alunos à prática do [...] e auxiliando à maior compreensão dos exercícios programáticos.

[...] servirão de material auxiliar em qualquer curso presencial ou à distância, relacionado ao conteúdo de [...] ministrados nas nossas uni- 
versidades brasileiras. Pode servir, também, para o estudo mais avançado de estudantes do ensino médio, em disciplinas de [...].

A proposta deste material é que o mesmo seja utilizado por todas as disciplinas de graduação que utilizem [...] em suas atividades de ensino, teóricas e práticas. Este material poderá auxiliar também as disciplinas [...], além dos estágios extra e intra-muros. Desta maneira alunos e docentes de outras disciplinas serão estimulados a sugerir melhorias ou novos objetos que possam ser de interesse do ensino [...]. Os alunos e docentes poderão ter conhecimento extra na literatura complementar sobre [...], além de desenvolver habilidades e recordar conhecimentos referentes aos procedimentos de uso dos [...].

E poucos apresentam uma proposta mais detalhada, de como este objeto poderia ser realmente inserido nas práticas docentes ou discentes das pessoas nele interessadas:

Videos de 10 min. sobre tipos de conhecimento, busca de informação cientifica e leitura crítica. Após assistirem-nos, os alunos deverão descrever e discutir casos [...] e preencher um portfólio dirigido. Ao final do módulo, os estudantes deverão ser capazes de diferenciar os diferentes tipos de conhecimento e compreender o impacto disto na tomada de decisões [...].

Ele está baseado em uma abordagem sócio-construtivista de aprendizagem, que acredita que as pessoas desenvolvem novos conhecimentos pela interação com o objeto a ser apreendido, e que a aprendizagem é intensificada quando ocorre através de interações sociais. [...] os usuários são desafiados a utilizar estes conteúdos apresentados anteriormente para escolher [...]. Para chegar a uma conclusão, deverão ser levadas em conta [...]. Para realizar esta atividade, foi desenvolvido um jogo [...], projetado para ser disputado por grupos de alunos reunidos em locais distintos, ou pelo menos em computadores diferentes.

O objeto de aprendizagem possibilitará interação entre os alunos de graduação e de pós-graduação interessados em [...] por meio de debates, com a participação de alunos e professor, a partir dos conteúdos disponibilizados pelo mencionado objeto, realizados através de ferramentas de interação como o Fórum, em ambiente virtual de aprendizagem [...]; 
bem como debate e seminário presencial, em sala de aula. As ferramentas de interação previstas também poderão ser utilizadas para a interação entre os alunos, com vistas à organização e à consecução das pesquisas suscitadas pelo objeto de ensino. Quanto à interatividade, o aluno poderá escolher o percurso de leitura dos hipertextos através da seleção dos hiperlinks; e deverá responder a exercícios interativos, especialmente desenvolvidos para o objeto.

Este tipo de informação, voltado especificamente às possibilidades de inserção do OA nas atividades de alunos e professores é, em alguns casos, apresentado de forma explícita (destacada em itens como Informações para Alunos e Informações para Professores), como em:

< para Alunos> A fim de obter uma compreensão dos processos envolvidos o aluno deve ter conhecimento prévio da [...]. Conhecer as definições de [...]. Poderá auxiliar-se com as leituras complementares incluidas nesta animação, mas maiores conhecimentos deverão ser obtidos dos livros correspondentes à [...].

<para Professores $>$ É com auxílio dessa atividade que serão enfocados conteúdos como [...]. Cada etapa dos processos poderá ser calculada pelos alunos e comparada com os dados apresentados na animação. $O$ aluno poderá visualizar diretamente a relação entre [...]

$<>$

< para Alunos> São apresentadas neste espaço maquetes virtuais e animações de [...]. A apresentação do material neste formato tem como objetivo dinamizar aulas práticas desta área, permitindo interações no processo ensino/aprendizado. As maquetes fazem parte de um acervo virtual de objetos de aprendizagem para as diferentes áreas de conhecimento que utilizam [...].

< para Professor> Estes objetos de aprendizagem têm por objetivo facilitar a compreensão do funcionamento e das aplicações de equipamentos utilizados em [...], a partir da visualização de [...]. Também são apresentados links com exemplos de aplicação e uso [...].

$<>$

$<$ para Alunos> Este objeto propõe-se a lhe auxiliar na elaboração de [...] no ambiente virtual de aprendizagem. Para isso você deverá [...]. Posteriormente, seu professor poderá lhe pedir para compartilhar essas informações com o grupo.

<para Professores> Ao iniciarmos um curso a distância, normalmente os alunos [...]. Esta dinâmica tem por objetivo facilitar a elaboração [...] e compartilhamento com os colegas. O professor poderá então [...]. 
Uma sugestão é convidá-los a [...]. Após essa atividade, o professor pode sugerir [...]

Mas, além de explícitas, algumas delas apresentam propostas concretas de uso do OA, como pode ser visto em:

<para Alunos> Esse material irá auxiliá-lo no estudo do [...], sendo um guia para conduzi-lo didaticamente às informações básicas, como [...], bem como as referências a serem consultadas sobre o assunto. Você poderá utilizá-lo como apoio às disciplinas que abordem [...], podendo navegar livremente conforme seu interesse ou sugestões de seu professor. A partir desse estudo, você será capaz de responder a questionamentos do tipo: [...] Através do estudo você irá adquirir e desenvolver habilidades e competências profissionais para o exercício dessa prática nas organizações com e sem fins lucrativos. Durante o seu estudo serás convidado à realização de atividades para ajudá-lo na compreensão dos conteúdos. Procure [...] para aplicar seus conhecimentos e praticar as instruções recebidas. Você terá instruções de como [...] no próprio objeto. Após, salve seu trabalho e encaminhe suas atividades para seu professor, a fim de obter um parecer sobre seu desempenho e progresso.

< para Professores> Poderá ser utilizado como apoio às aulas de disciplinas de [...], em nível de graduação, pós-graduação e extensão nas modalidades presenciais ou a distância (EAD). Apresenta uma estrutura modular com os conteúdos básicos abrangendo [...], contemplando [...], de forma a capacitar o estudante a formar juízo crítico a respeito da [...]. Você poderá integrá-lo em plataformas virtuais de aprendizagem (AVA) como parte de disciplinas ou mesmo utilizá-lo como material complementar, utilizando ferramentas de comunicação e interação como chats, fóruns, blogs, entre outras. Sugere-se a adoção de [...] para estudo de caso progressivo abrangendo todas as etapas do processo [...]. Em todos os módulos, apresentam-se propostas de tarefas a serem executadas. A entrega das mesmas pode ser direcionada para uma plataforma virtual ou mesmo enviada por e-mail, a fim de que o aluno obtenha feedback de suas atividades e receba contribuições de melhorias. Assim, espera-se que o estudante construa conhecimentos de modo a desenvolver habilidades para executar o processo de [...].

Quanto mais explícitos e detalhados estão os objetivos pedagógicos do objeto, mais condições seus usuários (alunos e/ou professores) têm de se 
apropriar destes recursos e estes serem, realmente, elementos facilitadores do processo de ensino e de aprendizado.

Um dos grandes diferenciais de objetos de aprendizagem, em relação aos softwares educacionais ou ambientes de aprendizagem, é eles serem criados com a finalidade de estarem disponíveis para a comunidade. E quanto mais autocontido, em termos de suficiência de conteúdo e de objetivo pedagógico, maior a possibilidade de quem o localizar em um Repositório de OAs entender como utilizá-lo e até propor diferentes usos para ele.

\section{Aprofundando a discussão}

Buscando conhecer o ponto de vista dos alunos sobre os OAs desenvolvidos - e por eles utilizados - foi elaborado um questionário, disponibilizado no formato online, constituído por duas seções: aspectos da interface e aspectos envolvendo a aprendizagem. O questionário era composto por quatro questões visando caracterizar o perfil dos alunos (curso, semestre, faixa etária etc.), onze questões de escolha múltipla e seis questões abertas. Esse questionário foi encaminhado aos professores para que os seus alunos avaliassem o objeto produzido por eles. Doze professores participaram e setenta e seis alunos responderam às questões propostas.

Dos dados coletados (CARNEIRO; SILVEIRA, 2012) destacam-se aqui aqueles referentes à aprendizagem através do objeto, buscando identificar se a explicitação dos objetivos pedagógicos pelo professor poderia ter auxiliado nesse processo. Dos respondentes, quase $70 \%$ dos alunos relataram ter utilizado o OA apenas seguindo as informações disponíveis, enquanto $23,6 \%$ o utilizaram após uma explicação do professor, o que poderia indicar que, neste segundo caso, os objetivos não estivessem claramente explicitados no OA.

A primeira questão aberta perguntava aos usuários qual o objetivo do $\mathrm{OA}$, podendo-se destacar respostas como "Para melhor fixação da matéria, poder visualizar aquilo que foi dado em aula, que vimos na teoria", e "O projeto serve como um material de apoio ao estudo do aluno". Quando perguntados se o material os havia ajudado a compreender o assunto abordado no OA, 70\% dos usuários responderam que "Ajudou" ou "Ajudou muito a compreensão", respostas justificadas por afirmações como "Quando vemos um assunto de forma dinâmica e aplicada, de forma que podemos interagir com ele, e não apenas vermos em sala de aula, sempre temos uma maior compreensão do conteúdo, e isto foi proporcionado pelo objeto". 
Quando perguntados se o objeto havia lhes oferecido uma forma diferente para compreender o assunto por ele tratado, mais de $90 \%$ dos respondentes disse que o objeto havia lhes oferecido uma forma diferente ou muito diferente de compreender o assunto, e entre as respostas os alunos comentaram que: "Proporcionou mais interatividade" e "O objeto proporciona uma forma diferente de aprendizado, uma vez que traz o conteúdo em hipertexto e vídeo, formas estas bastante interessantes e utilizadas na atualidade, o que propicia um aprendizado diferente do tradicional".

Perguntados sobre a utilização no contexto de sala de aula, a maioria dos alunos respondeu que foi uma atividade muito interessante e instigante que envolveu toda a turma; alguns outros citaram que a experiência foi individual ou através de ambiente virtual de aprendizagem. Essas afirmações podem indicar que os professores estão propondo OAs como suporte às aulas presenciais, de forma que eles não necessariamente precisassem ser autocontidos e explicitar objetivos de aprendizagem, que seriam explicados nos encontros presenciais. Isso foi comprovado através do registro das entrevistas com os professores, ao longo da produção dos OAs, quando um professor foi questionado sobre a falta de orientações sobre a animação proposta, ao que respondeu: "Ah, agora entendi, eu preciso escrever aqui aquilo que falo em sala de aula para meus alunos!". Essa afirmação aponta a necessidade permanente de capacitação e esclarecimento aos professores sobre o conceito de objetos de aprendizagem e suas potencialidades para apoio à aprendizagem.

Neste âmbito, para entender o ponto de vista dos professores em relação a este processo, foram entrevistados 58 professores que já haviam concluído a produção de seus OAs, com o objetivo de avaliar o processo de produção e o trabalho do NAPEAD. Naquele momento, a metodologia adotada baseava-se no modelo do INTERAD e iniciava-se com o preenchimento de um questionário, que pretendia auxiliar o professor na descrição do seu OA. No entanto, ao avaliar esse formulário, os professores apontaram diversos problemas, principalmente porque seu foco envolvia a descrição de características da interface que eles desconheciam. A entrevista pedagógica, entre professor proponente e um membro da coordenação do núcleo, focou-se na análise das informações prestadas naquele formulário, mas ainda pouco na descrição dos objetivos pedagógicos, provavelmente consequência também da pouca experiência da própria equipe de produção. As demais questões envolviam a análise da relação e trabalho com a equipe de bolsistas e as dificuldades encontradas.

Alguns professores, no entanto, relataram que a entrevista pedagógica auxiliou no processo de descrição do projeto, o que influenciou no produto final. 
"Essa entrevista foi com a ... e com a ..., [e] serviu para deixar claro o que é o OA, os seus objetivos, o foco a ser definido e os limites para poder fazê-lo como tecnologias e tempo. No meu objeto por exemplo é um hipertexto que trabalha com 4 linhas de pesquisa, e nessa entrevista foi definido como elas seriam inseridas; também dessa entrevista surgiu a ideia do vídeo, que eu não tinha pensado antes, mas me foi sugerido e eu gostei. Acredito que essa entrevista sirva como 'Ponto de Partida' para o início do projeto de criação de um OA”. (entrevistado GL, nov. 2012).

"Foi muito importante esta reunião, pois deu clareza às informações, e no que eles precisariam da gente; serviu também para homogeneizar a linguagem de trabalho e refinar as minhas ideias para criar uma coisa única e sólida de ser criada. Gostei bastante da equipe, e o projeto conseguiu sair dentro do previsto; os maiores atrasos foram por minha culpa, no envio do material, pois o meu objeto era complexo e envolvia hipertexto, vídeo e animação”. (entrevistado MA, nov. 2012).

Das diversas questões levantadas, observa-se a importância da apropriação, pela equipe, da concepção e conceito claro do que é um objeto de aprendizagem e o que ele deve conter. Sem isso, o trabalho se torna extremamente técnico, focado na produção de animações, vídeos ou hipertextos, desconectados das condições de reusabilidade e potencial pedagógico.

\section{Considerações finais}

Pouco se encontra sobre relatos de usos de OAs no ensino superior. No período que segue aos estudos de Wiley (2000), vários autores demonstraram preocupação com a produção de materiais didáticos para apoiar cursos a distância (IP; MORRISON, 2001; METROS; BENNET, 2002; BOYLE et al., 2003; BOYLE, 2010; RITZHAUPT, 2010; NIKOLOPOULOS et al., 2012), com algum foco na perspectiva pedagógica. No entanto, a maior parte dos pesquisadores foca-se nas questões tecnológicas associadas à produção, à busca da reusabilidade e da padronização. Mais recentemente, o foco passa para a constituição de repositórios e referatórios, onde os OAs possam ser localizados, referenciados e reutilizados (GALAFASSI et al., 2013). 
Nos casos aqui analisados, observamos que a maioria dos professores busca materiais didáticos para apoiar as aulas presenciais, em consonância com as políticas implementadas pela Secretaria de Educação a Distância (SEAD) da UFRGS. A SEAD, desde sua criação em 2001, tem incentivado a inserção das tecnologias no ensino presencial, principalmente de graduação, com o intuito de envolver os professores, romper com as barreiras no uso das tecnologias e, assim, inseri-los nas ações de educação a distância.

Dessa forma, os objetos produzidos até o momento apontam para um uso individualizado pelos alunos, como complemento aos estudos após ou durante as aulas presenciais. Alguns professores implementaram atividades ou questões para incentivar os alunos a buscar novos conhecimentos e propiciar a discussão posterior, com o apoio de recursos dos ambientes virtuais de aprendizagem.

Já a metodologia de produção de objetos de aprendizagem do NAPEAD baseia-se na ideia de que o professor é o responsável pelo projeto, cabendo à equipe do núcleo apoiar e orientar sobre a implementação dessa proposta. Esta decisão também implica em respeitar a opinião do professor, mesmo nos casos nos quais a equipe gostaria de intervir.

Considerando a pouca experiência dos professores na criação de materiais didáticos digitais, são oferecidas sistematicamente capacitações, em que são apresentados os conceitos básicos sobre objetos de aprendizagem e as tecnologias que permitem implementá-los. Ao longo do tempo, também se identificou a necessidade de orientações mais específicas sobre como construir storyboards, mapas de navegação e roteiros para produção de vídeos, o que tem sido atendido através de oficinas e cursos de curta duração.

A partir da observação da experiência e relatos de uso de OAs discutidos neste artigo, entendemos que - para que se possam criar Objetos de Aprendizagem que sejam, realmente, elementos facilitadores do processo de ensino e aprendizagem, seja este a distância ou não - se faz necessário que $o$ professor compreenda o conceito de OA de forma plena, como algo que precisa explicitar seu objetivo pedagógico, seja autocontido, possa ser agregado a um todo maior, incentive/estimule o aluno a querer explorá-lo e, a partir daí, aprenda coisas novas e queira buscar outros conhecimentos. Mas para isto, é necessário que se intensifiquem as capacitações realizadas e que se disponibilize a estes professores - produtores de OAs - apoio de equipe competente que considere também os aspectos da interface, de reusabilidade (padrões, metadados) e até de acessibilidade (ampliando o espectro de uso destes objetos. 


\section{REFERÊNCIAS}

APEL, M. A. Operações Unitárias Farmacêuticas: Moinho coloidal [gravação de vídeo]. Vídeo (1 min., 38 s.). 2011. Disponível em: < http://www.ufrgs.br/napead/repositorio/ objetos/ operacoes-unitarias-farmaceuticas/>. Acesso em: 14/04/2014.

BEHAR, P.A. (org.). Modelos Pedagógicos em Educação a Distância. Porto Alegre: Artmed, 2009.

BOYLE, T. Layered learning design: towards an integration of learning design and learning object perspectives. Computers \& Education, v. 54, p. 661-668, 2010.

BOYLE, T.; BRADLEY, C.; CHALK, P.; JONES, R.; HAYNES, R.; PICKARD, P. Can learning objects contribute to pedagogical improvement in higher education: lessons from a case study. ICS Subject Centre of the Higher Education Academy University of Ulster, UK. mar. 2003. Disponível em: <http://78.158.56.101/archive/ics/ resources/rlos/ introprog/papers/ CAL_Objects_paper.doc $>$. Acesso em: 15/03/2014.

CARNEIRO, M. L. F.; SILVEIRA, M. S. Objetos de aprendizagem sob o ponto de vista dos alunos: um estudo de caso. RENOTE. Revista Novas Tecnologias na Educação, v. 10, n.3, p. 363-393, 2012.

GALAFASSI, F. P.; GLUZ, J. C.; GALAFASSI, C. Análise crítica das pesquisas recentes sobre as tecnologias de objetos de aprendizagem e ambientes virtuais de aprendizagem. Revista Brasileira de Informática na Educação. v. 21, n. 3, 2013. Disponível em: <http:// www.br-ie.org/pub/index.php/rbie/article/view/2351/2457>. Acesso em: 2/03/2014.

HODGINS, H. W. The future of learning objects. In: WILEY, D. A. (Ed.). The instructional use of learning objects: online version. 2000. Disponível em: $<\mathrm{http}: / /$ reusability. org/read/chapters/hodgins.doc >. Acesso em: 15/03/2014.

HODGINS, H. W. The future of learning objects. e-Technologies in Engineering Education: learning outcomes providing future possibilities. In: LOHMANN, J.; CORRADINI, M. (Eds.). ECI Symposium Series. v. P01, 2002. p. 76-82. Disponível em: <http:// dc.engconfintl.org/etechnologies/11>. Acesso em: 15/03/2014.

INEP. Sinopses Estatísticas da Educação Superior - Graduação. 2014. Disponível em: $<$ http://portal.inep.gov.br/superior-censosuperior-sinopse>. Acesso em: 7/04/2014.

INSTITUTE OF ELECTRICAL AND ELECTRONICS ENGINEERS (IEEE). Draft Standard for Learning Object Metadata. Learning Technology Standards Committee. jul. 2002. Disponível em: $<$ http://ltsc.ieee.org/wg12/files/LOM_1484_12_1_v1_Final_Draft. pdf $>$. Acesso em: 14/04/2014.

IP, A.; MORRISON, I. Learning Objects in different pedagogical paradigms. 18th Annual Conference of the Australasian Society for computers in Learning In Tertiary Education. University of Melbourne. Austrália, dez. 2001. Disponível em: <http://www.ascilite.org. au/conferences/melbourne01/pdf/papers/ipa.pdf > Acesso em: 10/04/2014. 
JOHNSON, K.; HALL, T. Granularity, Reusability and Learning Objects. In: KOOHANG, A.; HARMAN, K. (Ed.). Learning objects: theory, praxis, issues and trends. Santa Rosa, California: Informing Science Press, 2007. p. 181-207.

JOHNSON, L. F. Elusive Vision: challenges impeding the learning object economy. Macromedia White Paper. New Media Consortium, jun. 2003. Disponível em: $<$ http:// www.nmc.org/pdf/Elusive_Vision.pdf>. Acesso em: 20/03/2013.

KAY, R.; KNAACK, L. A formative analysis of individual differences in the effectiveness of learning objects in secondary school. Computers \& Education, London, v. 51, n. 1, p. $1304-1320$, nov. 2008.

KOOHANG, A.; HARMAN, K. (Ed.). Learning Objects: theory, praxis, issues and trends. Santa Rosa, California: Informing Science Press, 2007.

METROS, S. Learning Objects: a rose by any other name. EDUCAUSE Review, v. 40, n. 4, jul./ago. 2005, p. 12-13. Disponível em: <https://net.educause.edu/ir/library/pdf/ ERM05410.pd > . Acesso em: 2/03/2014.

METROS, S.; BENNET, K. Learning Objects in Higher Education. EDUCAUSE, v. 2002, n. 19, out. 2002. p. 1-10. Disponível em: <https://net.educause.edu/ir/library/pdf/ ERB0219.pdf>. Acesso em: 30/03/2014.

NIKOLOPOUlOS, G.; SOLOMOU, G.; PIERRAKEAS, C.; KAMEAS, A. Modeling the characteristics of a learning object for use within e-learning applications. BCI'12. Proceedings of the Fifth Balkan Conference in Informatics. p. 112-117., NY, USA: ACM New York, 2012.

NITZKE, J. Vegetais Congelados [objeto de aprendizagem]. Disponível em: $<$ http:// www.ufrgs.br/napead/repositorio/objetos/vegetais-congelados/>. Acesso em: 14/04/2014.

NITZKE; J.; CARNEIRO, M. L.; PASSOS, P. C. Gestão do desenvolvimento de objetos de aprendizagem digitais. Sexto Congresso Latinoamericano de Objetos de Aprendizagem. Anais... Montevideo, Uruguay, 2011. Disponível em: $<$ http://laclo2011.seciu.edu. uy/publicacion/laclo/laclo2011_submission_111.pdf>. Acesso em: 04/04/2014.

PASSOS, P. C. S. J. Interad: uma metodologia para design de interface de materiais educacionais digitais. 182 f. Dissertação (Mestrado) - Curso de Pós-Graduação em Educação, Universidade Federal do Rio Grande do Sul, Porto Alegre, 2011. Disponível em: <http://hdl.handle.net/10183/32234>. Acesso em: 06/04/2014.

POLSANI, P. Use and abuse of reusable learning objects. Journal of Digital Information, v. 3, n. 4, 2003. Disponível em: < http://journals.tdl.org/jodi/index.php/jodi/article/ view/89/88>. Acesso em: 04/04/2014.

RITZHAUPT, A. Learning object systems and strategy: a description and discussion. Interdisciplinary Journal of e-learning and Learning Objects, v. 6, 2010. Disponível em: <http:/www.ijello.org/Volume6/IJELLOv6p217-238Ritzhaupt701.pdf>. Acesso em: 10/03/2014. 
SERNA, E.; CASTRO, C. A.; BOTERO, R. ISDOA: Ingeniería de software para desarrollar objetos de aprendizage. EATIS 2012. Anais... Valencia, Espanha, maio 2012.

SILVEIRA, M. S.; CARNEIRO, M. L. F. Diretrizes para a avaliação da usabilidade de objetos de aprendizagem. Anais do Simpósio Brasileiro de Informática na Educação. Rio de Janeiro, Brasil, nov. 2012. Disponível em: <http:/www.br-ie.org/pub/index.php/ sbie/article/view/1713/1474>. Acesso em: 08/07/2013.

SCHWANCK, D.I.; CARNEIRO, M.L.F.; SILVEIRA, M.S. A influência da área de atuação do professor na interface de objetos de aprendizagem por ele idealizados. Revista Novas Tecnologias na Educação, PPGIE/UFRGS, v.12, n. 1, 2014. Disponível em: <http:// seer.ufrgs.br/index.php/renote/article/view/49833/31191>. Acesso em: 12/11/2014.

TAROUCO, L. M. R.; FABRE, M. J. M.; TAMUSIUNAS, F. R. Reusabilidade de objetos educacionais. Revista Novas Tecnologias na Educação, PPGIE/UFRGS, v.1., n.1., 2003. Disponível em: < http://seer.ufrgs.br/index.php/renote/article/view/13628/7697>. Acesso em 10/11/2014.

WEIBEL, D. E. $1^{a}$ e $2^{a}$ Leis da Termodinâmica [objeto de aprendizagem]. Disponível em: <http://www.ufrgs.br/napead/repositorio/objetos/leis-da-termodinamica/>. Acesso em: 14/04/2014.

WILEY, D. The Post-LEGO Learning Object. nov, 1999. Disponível em: <http://opencontent.org/docs/post-lego.pdf>. Acesso em: 14/04/2014.

WILEY, D. A. Learning Object Design and Sequencing Theory. Thesis (Philosophy Course), Department Of Instructional Psychology And Technology, Brigham Young University, Provo, Utah, USA, 2000.

WILEY, D.A. Connecting learning objects to instructional design theory: a definition, a metaphor, and a taxonomy. In: WILEY, D. A. (Ed.). The instructional use of learning objects: Online Version. 2002. Disponível em: $<$ http://reusability.org/read/chapters/wiley. doc $>$. Acesso em: 10/03/2014.

Texto recebido em 22 de novembro de 2014. Texto aprovado em 09 de dezembro de 2014. 